\title{
FAKTOR-FAKTOR YANG BERHUBUNGAN DENGAN PEMBERIAN ASI EKSKLUSIF
}

\author{
Nopita Akbar1), Fitria2), Ratna Dewi Putri3) \\ ${ }^{1}$ Prodi Kebidanan Universitas Malahayati \\ Email: novitaakbar58@gmail.com \\ 2Prodi Kebidanan Universitas Malahayati \\ Email: jimy.margono@gmail.com \\ ${ }^{3}$ Prodi Kebidanan Universitas Malahayati \\ Email: ratnadewi070787@gmail.com
}

\begin{abstract}
Background: Early breastfeeding has a positive impact on both mother and baby. The highest coverage of exclusive breastfeeding in Pesawaran Regency in Puskesmas Gedong Tataan was 97.65\%, the lowest achievement was at Puskesmas Kedondong at $14.24 \%$ and Puskesmas Kalirejo at $50.00 \%$. In Kalirejo Health Center the exclusive coverage of ASI in 2016 was $69.02 \%$ and in 2017 it was $50.00 \%$. Based on the data seen a decrease in exclusive breastfeeding in the area of Kalirejo Health Center.

Purpose: To determine the factors associated with exclusive breastfeeding

Methods: This type of quantitative research is cross sectional study. The entire population of 94 respondents with a total sample of 77 respondents of mothers who have infants 7-12 months, the research technique sampling is purposive sampling. Data analysis by uni variate and bivariate (ujichi-square).

Result:The results of the study are known from 77 respondents obtained results of mothers who are not exclusive breastfeeding as many as 49 (63.6\%) respondents. Working mothers were $35(45.5 \%)$ respondents. 54 less knowledgeable mothers (70.1\%) respondents. mothers with no nipple abnormalities were 59 (76.6\%) respondents. Support of negative health health workers was 29 (37.7\%). There is a work relationship with exclusive breastfeeding ( $p$-value $=0,000$ and OR10,333). There is a relationship of knowledge with exclusive breastfeeding ( $p$-value $=0,000$ and $O R$ 15,840). There is a correlation between nipple abnormalities and exclusive breastfeeding ( $p$-value 0.035 and OR 5.735). There is a relationship between health personnel support and exclusive breastfeeding ( $p$-value $=0.014$ and OR 4,416).

Conclusion: Factors related to exclusive breastfeeding are occupation, mother's knowledge, abnormalities of nipple feeding, and support of health workers

Suggestion:For this reason, counseling is needed, motivation about the knowledge of breastfeeding to mothers in order to provide exclusive breastfeeding to babies.
\end{abstract}

Keywords: Exclusive breastfeeding, knowledge, occupation, nipple abnormalities, support of health workers

\section{ABSTRAK}

Latar Belakang: Menyusui sejak dini mempunyai dampak yang positif baik bagi ibu maupun bayinya. Cakupan ASI eksklusif di Kabupaten Pesawaran tertinggi di Puskesmas Gedong Tataan sebesar 97,65\% pencapaian terendah ada di Puskesmas Kedondong sebesar 14,24\% dan Puskesmas Kalirejo sebesar 50,00\% Pada Puskesmas Kalirejo cakupan ASI eksklusif tahun 2016 sebesar 69,02\% dan di tahun 2017 sebesar $50.00 \%$. Berdasarkan data terlihat penurunan pemberian ASI eksklusif di wilayah Puskesmas Kalirejo.

Tujuan: Untuk mengetahui factor yang berhubungan denganpemberian ASI Eksklusif

Metode: Jenis penelitian kuantitatif pendekatancross sectional study. Seluruh Populasi 94 responden dengan total sampel 77 Responden ibu yang mempunyai bayi 7 - 12 bulan, teknik penelitian sampling secara purposive sampling. Analisis data secara uni variat dan bivariate ( ujichi-square ).

Hasil penelitian diketahui dari 77 responden didapatkan hasil ibu yang tidak ASI eksklusif sebanyak 49 $(63,6 \%)$ responden. Ibu yang bekerja sebanyak $35(45,5 \%)$ responden. Ibu yang berpengetahuan kurang sebanyak $54(70,1 \%)$ responden . ibu yang tidak ada kelainan puting susu sebanyak $59(76,6 \%)$ responden.Dukungan tenaga kesehatan kesehatan negatif sebanyak $29(37,7 \%)$. Ada hubungan pekerjaan dengan pemberian ASI eksklusif ( $p$-value $=0,000$ dan OR10,333). Ada hubungan pengetahuan dengan pemberian ASI eksklusif ( $p$-value $=0,000$ dan OR 15,840). Ada hubungan kelainan puting susu dengan 
pemberian ASI eksklusif ( $p$-value 0,035 dan OR 5,735). Ada hubungan dukungan tenaga kesehatan dengan pemberian ASI eksklusif ( $p$-value $=0,014$ dan OR 4,416).

Kesimpulan: Faktor yang berhubungan dengan pemberian ASI Eksklusif yaitu pekerjaan, pengetahuan ibu,kelainan putting susu, dan dukungan tenaga kesehatan

Saran: Untuk itu di perlukan penyuluhan, motivasi tentang pengetahuan pemberian Asi kepada ibu agar dapat memberikan Asi ekslusif kepada bayi.

Kata kunci: ASI Eksklusif, pengetahuan, pekerjaan, kelainan puting susu, dukungan tenaga kesehatan

\section{PENDAHULUAN}

Menyusui sejak dini mempunyai dampak yang positif baik bagi ibu maupun bayinya.Manfaat memberikan Air Susu Ibu (ASI) bagi ibu tidak hanya menjalin kasih sayang, tetapi dapat mengurangi perdarahan setelah melahirkan, mempercepat pemulihan kesehatan ibu, menunda kehamilan, mengurangi risiko terkena kanker payudara dan merupakan kebahagiaan tersendiri bagi ibu.ASI merupakan salah satu makanan yang sempurna dan terbaik bagi bayi karena mengandung unsurunsur gizi yang dibutuhkan oleh bayi untuk pertumbuhan dan perkembangan yang optimal.Pemberian ASI perlu diberikan secara eksklusif sampai umur 6 (enam) bulan dan dapat dilanjutkan sampai anak berumur 2 (dua) tahun.Walaupun demikian masih terdapat kendala dalam pemberian ASI eksklusif karena belum ada sistem yang dapat diandalkan untuk memantau pemberian ASI eksklusif (Jateng, 2011).

Di Amerika sebanyak $44 \%$ bayi diberikan ASI eksklusif selama 3 bulan dan hanya sebanyak $22 \%$ diberikan selama 6 bulan. Secara global, tidak lebih dari $35 \%$ bayi mendapatkan ASI selama kurang dari empat bulan, di Mesir $79 \%$ bayi di bawah usia dua bulan diberikan ASI. Namun, proporsi ASI eksklusif menurun dengan cepat pada saat bayi berusia 4-5 bulan.Sekitar tujuh dari sepuluh bayi menerima beberapa bentuk suplemen (Febriyanti, H. (2018).

Di Indonesia, angka pemberian ASI eksklusif pada bayi berumur 0-6 bulan mencapai angka $55,7 \%$. Terdapat 23 provinsi yang mempunyai presentase ASI eksklusif di atas angka Nasional $(55,7 \%)$ yang tertinggi di NTB $(85,9 \%)$ dan terendah Sulawesi Utara $(26,3 \%)$ dan Lampung (54,9\%) merupakan 9 terendah dari seluruh provinsi di Indonesia (KeMenKes, R. I. 2016).

Sementara itu, data yang dikeluarkan oleh Dinkes Provinsi Lampung bahwa pemberian ASI eksklusif pada bayi 0-6 bulan berfluktuatif, pada tahun 2012 sebesar 30,1\%, tahun 2013 kenaikan yang bermakna menjadi $42,0 \%$ dan tahun 2014 cakupan bayi mendapatkan ASI Ekslusif sebanyak 82,3\% namun di tahun 2015 cakupan ASI eksklusif mengalami penurunan menjadi $57,7 \%$ bayi dimana angka ini masih di bawah target yang diharapkan sebesar 80\% (Lampung, 2016).

Pencapaian ASI eksklusif tahun 2016 tertinggi di Kabupaten Mesuji sebanyak 85,28\% dan terendah di Kota Metro sebanyak 33,50\% sedangkan di Kabupaten Pesawaran sebanyak 49,76\% (Lampung, 2017). Berdasarkan data terlihat bahwa Kabupaten Pesawaran dalam cakupan pemberian ASI eksklusif masih di bawah pencapaian provinsi sebesar $56,26 \%$.

Data yang diperoleh dari Dinas Kesehatan Kebupaten Pesawaran tahun 2016 bayi yang mendapatkan ASI eksklusif sebesar $49,76 \%$ dan di tahun 2017 sebesar 49,59\% (Pesawaran, 2018). Berdasarkan laporan bulanan terlihat bahwa pencapaian ASI sebesr $47.08 \%$ terjadi penurunan dalam pemberian ASI eksklusif di Kabupaten Pesawaran.

Cakupan ASI eksklusif di Kabupaten Pesawaran tertinggi di Puskesmas Gedong Tataan sebesar $97,65 \%$ pencapaian terendah ada di Puskesmas Kedondong sebesar $14,24 \%$ dan Puskesmas Kalirejo sebesar 50,00\% (Pesawaran, D. K. K., 2018). Pada Puskesmas Kalirejo cakupan ASI eksklusif tahun 2016 sebesar $69,02 \%$ dan di tahun 2017 sebesar $50.00 \%$. Berdasarkan data terlihat penurunan pemberian ASI eksklusif di wilayah Puskesmas Kalirejo (Pesawaran, 2018).

Hasil penelitian Rahmawati (2010) Berdasarkan hasil prasurvei yang dilakukan dengan wawancara singkat kepada 22 ibu yang memiliki bayi usia 7-12 bulan di wilayah kerja Puskesmas Kalirejo tanggal 3-10 Januari 2019, diketahui dari 22 ibu tersebut sebanyak $11(50 \%)$ ibu tidak memberikan ASI eksklusif, sebanyak $8(36,4 \%)$ ibu memberikan ASI eksklusif hanya sampai 4 bulan dan sudah biasa terjadi karena berdasarkan pengalaman orang tua ataupun mertua dari ibu yang tinggal serumah, sebanyak $2(9,1 \%)$ orang ibu tidak memberikan ASI eksklusif dengan alasan ibu mulai bekerja dan malas untuk memompa ASI nya terlebih dahulu. Sebanyak $1(4,5 \%)$ orang ibu tidak memberikan ASI eksklusif karena ada gangguan di payudara, dimana payudara bengkak dan 
mengeluarkan nanah. Dari 22 responden tersebut sebanyak $15(68,1 \%)$ tidak mengetahui apa itu ASI ekslusif (ibu mengetahui ASI eksklusif hanya sampai 4 bulan bukan sampai 6 bulan) dan hanya 7 $(31,8 \%)$ yang mengetahui pengertian dari ASI eksklusif, dan dari 22 orang sebanyak12 $(54,5 \%)$ adalah ibu yang tidak bekerja dan $10(45,4 \%)$ ibu bekerja.

\section{METODE PENELITIAN}

Jenis penelitian atau metode penelitian kuantitatif, Rancangan penelitian analitik dengan pendekatan Cross Sectional (Swarjana, I. K., \& SKM, M. (2012). Waktu penelitian telah dilaksanakan pada bulan Februari - Juli 2019 di Puskesmas Kalirejo Kabupaten Pesawaran. Populasi penelitian ini adalah seluruh ibu yang memiliki bayi 7-12 bulan di Puskesmas Kalirejo Kabupaten Pesawaran, dimana berdasarkan data Posyandu bulan April 2019, terdapat 94 bayii berusia 7-12 bulan. Sampel yang berjumlah 77 responden. Variabel Bebas penelitian ini pengetahuan, pekerjaan, kelainan anatomis pada puting susu, dan dukungan tenaga kesehatan. Variabel Terikat adalahpemberian ASI ekslusif.

\section{HASIL DAN PEMBAHASAN}

\section{Analisis Univariat}

Analisa yang digunakan dalam penelitian ini adalah analisa univariat yang dilakukan pada tiap variabel dalam bentuk tabel distribusi frekuensi responden berdasarkan faktor-faktor yang berhubungan dengan pemberian ASI eksklusif di Puskesmas Kalirejo Kabupaten Pesawaran tahun 2019. Hasil penelitian terhadap 77 responden didapat :

\section{Tabel 1 Distribusi frekuensi Pemberian ASI Eksklusif}

\begin{tabular}{lcc}
\hline Pemberian ASI Eksklusif & $\mathrm{N}$ & $\%$ \\
\hline Tidak Eksklusif & 49 & 63,6 \\
ASI Eksklusif & 28 & 36,4 \\
$\quad$ Total & 77 & 100,0 \\
\hline
\end{tabular}

Berdasarkan tabel 1 dapat diketahui bahwa dari 77 responden didapatkan hasil ibu yang tidak ASI eksklusif yaitu sebanyak $49(63,6 \%)$ responden dan ibu yang ASI ekslusif sebanyak $28(36,4 \%)$ responden.

Berdasarkan tabel dapat diketahui bahwa dari 77 responden didapatkan hasil ibu yang bekerja yaitu sebanyak $35(45,5 \%)$ responden dan ibu yang tidak bekerja yaitu sebanyak $42(54,5 \%)$ responden.
Tabel 2 Distribusi frekuensi pekerjaan pada ibu

\begin{tabular}{ccc}
\hline Pekerjaan & $\mathrm{N}$ & $\%$ \\
\hline Bekerja & 35 & 45,5 \\
Tidak bekerja & 42 & 54,5 \\
Total & 77 & 100,0 \\
\hline
\end{tabular}

Tabel 3 Distribusi frekuensi pengetahuan pada ibu

\begin{tabular}{lcc}
\hline Pengetahuan & $\mathrm{N}$ & $\%$ \\
\hline Kurang Baik & 54 & 70,1 \\
Baik & 23 & 29,9 \\
Total & 77 & 100,0 \\
\hline
\end{tabular}

Berdasarkan tabel dapat diketahui bahwa dari 77 responden didapatkan hasil ibu yang berpengetahuan kurang yaitu sebanyak $54(70,1 \%)$ responden dan ibu yang berpengetahuan baik yaitu sebanyak $23(29,9 \%)$ responden.

\section{Tabel 4 Distribusi kelainan Puting susu pada ibu}

\begin{tabular}{lcc}
\hline Fisik & $\mathrm{N}$ & $\%$ \\
\hline Ada kelainan & 18 & 23,4 \\
Tidak ada kelainan & 59 & 76,6 \\
Total & 77 & 100,0 \\
\hline
\end{tabular}

Berdasarkan tabel dapat diketahui bahwa dari 77 responden didapatkan hasil ibu yang ada kelainan yaitu sebanyak $18(23,4 \%)$ responden dan ibu yang tidak ada kelainan yaitu sebanyak 59 $(76,6 \%)$ responden.

\section{Tabel 5 Distribusi frekuensi dukungan tenaga kesehatan pada ibu hamil}

\begin{tabular}{lcc}
\hline Dukungan tenaga kesehatan & $\mathrm{N}$ & $\%$ \\
\hline Negatif & 29 & 37,7 \\
Positif & 48 & 62,3 \\
Total & 77 & 100,0 \\
\hline
\end{tabular}

Berdasarkan tabel 5 dapat diketahui bahwa dari 77 responden didapatkan hasil dukungan tenaga kesehatan negatif yaitu sebanyak 29 $(37,7 \%)$ responden dan dukungan tenaga kesehatan positif yaitu sebanyak 48 (62,3\%) responden. 
Tabel 6 Hubungan pengetahuan dengan Pemberian ASI Eksklusif

\begin{tabular}{|c|c|c|c|c|c|c|c|c|}
\hline \multirow{3}{*}{ Pengetahuan } & \multicolumn{4}{|c|}{ Pemberian ASI Eksklusif } & \multirow{2}{*}{\multicolumn{2}{|c|}{ Total }} & \multirow{3}{*}{$p$-value } & \multirow{3}{*}{$\begin{array}{c}\text { OR } \\
95 \% \mathrm{Cl}\end{array}$} \\
\hline & \multicolumn{2}{|c|}{ Tidak Eksklusif } & \multicolumn{2}{|c|}{ ASI Eksklusif } & & & & \\
\hline & $\mathrm{N}$ & $\%$ & $\mathrm{~N}$ & $\%$ & $\mathrm{~N}$ & $\%$ & & \\
\hline Kurang & 44 & 81,5 & 10 & 18,5 & 54 & 100,0 & & 15,840 \\
\hline Baik & 5 & 21,7 & 18 & 78,3 & 23 & 100,0 & 0,000 & $(4,745-18,879)$ \\
\hline Total & 49 & 63,6 & 28 & 36,4 & 77 & 100,0 & & \\
\hline
\end{tabular}

Berdasarkan tabel dapat diketahui dari 54 responden dengan ibu berpengetahuan kurang sebanyak $44(81,5 \%)$ responden yang memberikan Asi tidak eksklusif dan sebanyak $10(18,5 \%)$ responden yang memberikan ASI eksklusif. Dan dari 23 responden dengan ibu berpengetahuan baik sebanyak $5(21,7 \%)$ yang memberikan ASI tidak eksklusif dan sebanyak $18 \quad(78,3 \%)$ yang memberikan ASI Eksklusif.
Hasil uji statistik didapat nilai $p$ value $0,000<$ a $(0,000<0,05)$ dimana $\mathrm{HO}$ ditolak sehingga dapat disimpulkan bahwa ada hubungan pengetahuan dengan pemberian ASI eksklusif di Puskesmas Kalirejo Kabupaten Pesawaran tahun 2019. Dengan nilai OR didapat 15,840 artinya ibu dengan pengetahuan kurang mempunyai resiko 15 kali untuk memberikan ASI tidak eksklusif dibandingkan ibu yang berpengetahua baik

Tabel 7 Hubungan pekerjaan dengan Pemberian ASI Eksklusif

\begin{tabular}{|c|c|c|c|c|c|c|c|c|}
\hline \multirow{3}{*}{ Pekerjaan } & \multicolumn{4}{|c|}{ Pemberian ASI Eksklusif } & \multirow{2}{*}{\multicolumn{2}{|c|}{ Total }} & \multirow{3}{*}{$p$-value } & \multirow{3}{*}{$\begin{array}{c}\text { OR } \\
95 \% \mathrm{Cl}\end{array}$} \\
\hline & \multicolumn{2}{|c|}{ Tidak Eksklusif } & \multicolumn{2}{|c|}{ ASI Eksklusif } & & & & \\
\hline & $n$ & $\%$ & $\mathrm{~N}$ & $\%$ & $\mathrm{~N}$ & $\%$ & & \\
\hline Bekerja & 31 & 88,6 & 4 & 11,4 & 100,0 & 100,0 & 0 & 10,333 \\
\hline Tidak Bekerja & 18 & 42,9 & 24 & 57,1 & 100,0 & 100,0 & 0,000 & $(3,089-34,562$ \\
\hline Total & 49 & 63,6 & 28 & 36,4 & 100,0 & 100,0 & & \\
\hline
\end{tabular}

Berdasarkan tabel dapat diketahui dari 35 responden dengan ibu bekerja sebanyak $31(88,6 \%)$ responden yang memberikan ASI tidak eksklusif dan sebanyak $4(11,4 \%)$ responden yang memberikan ASI eksklusif. Sedangkan dari 42 responden dengan ibu tidak bekerja sebanyak 18 $(42,9 \%)$ yang memberikan ASI tidak eksklusif dan sebanyak $24 \quad(57,1 \%)$ yang memberikan ASI Eksklusif.
Hasil uji statistik didapat nilai $p$ value $0,000<$ a $(0,000<0,05)$ dimana $\mathrm{H} 0$ ditolak sehingga dapat disimpulkan bahwa ada hubungan pekerjaan dengan pemberian ASI eksklusif di Puskesmas Kalirejo Kabupaten Pesawaran tahun 2019. Dengan nilai OR didapat 10,333 artinya ibu yang bekerja mempunyai resiko 10 kali untuk memberikan ASI tidak eksklusif dibandingkan ibu yang tidak bekerja.

Tabel 8 Hubungan kelainan Puting susu dengan Pemberian ASI Eksklusif

\begin{tabular}{|c|c|c|c|c|c|c|c|c|}
\hline \multirow{3}{*}{$\begin{array}{l}\text { Kelainan Puting } \\
\text { susu }\end{array}$} & \multicolumn{4}{|c|}{ Pemberian ASI Eksklusif } & \multirow{2}{*}{\multicolumn{2}{|c|}{ Total }} & \multirow{3}{*}{$p$-value } & \multirow{3}{*}{$\begin{array}{c}\text { OR } \\
95 \% \mathrm{Cl}\end{array}$} \\
\hline & \multicolumn{2}{|c|}{ Tidak Eksklusif } & \multicolumn{2}{|c|}{ ASI Eksklusif } & & & & \\
\hline & $\mathrm{n}$ & $\%$ & $\mathrm{~N}$ & $\%$ & $\mathrm{~N}$ & $\%$ & & \\
\hline Ada kelainan & 15 & 88,2 & 2 & 11,8 & 17 & 100,0 & \multirow{3}{*}{0,035} & \multirow{3}{*}{$\begin{array}{c}5,735 \\
(1,204-27,328\end{array}$} \\
\hline Tidak ada kelainan & 34 & 56,7 & 26 & 43,3 & 60 & 100,0 & & \\
\hline Total & 49 & 63,6 & 28 & 36,4 & 77 & 100,0 & & \\
\hline
\end{tabular}

Berdasarkan tabeldapat diketahui dari 17 responden yang ada kelainan, sebanyak $15(88,2 \%)$ responden yang memberikan ASI tidak eksklusif dan sebanyak $2(11,8 \%)$ responden yang memberikan ASI eksklusif. Dan dari 60 responden yang tidak ada kelainan, sebanyak $34(56,7 \%)$ responden memberikan ASI tidak Eksklusif dan sebanyak $26(43,3 \%)$ responden memberikan ASI eksklusif.

Hasil uji statistik didapat nilai $p$ value $0,035<$ a $(0,05)$ dimana $\mathrm{HO}$ ditolak sehingga dapat disimpulkan bahwa ada hubungan kelainan Puting susu dengan pemberian ASI eksklusif di Puskesmas Kalirejo Kabupaten Pesawaran tahun 
2019. Dengan nilai OR didapat 5.735 artinya ibu yang ada kelainan Puting susu mempunyai resiko 5,7 kali untuk memberikan ASI tidak eksklusif dibandingkan ibu yang tidak ada kelainan bentuk payudara.

Tabel 9 Hubungan dukungan tenaga kesehatan dengan Pemberian ASI Eksklusif

\begin{tabular}{|c|c|c|c|c|c|c|c|c|}
\hline \multirow{3}{*}{$\begin{array}{l}\text { Dukungan } \\
\text { petugas } \\
\text { kesehatan }\end{array}$} & \multicolumn{4}{|c|}{ Pemberian ASI Eksklusif } & \multirow{2}{*}{\multicolumn{2}{|c|}{ Total }} & \multirow{3}{*}{$p$-value } & \multirow{3}{*}{$\begin{array}{c}\text { OR } \\
95 \% \mathrm{Cl}\end{array}$} \\
\hline & \multicolumn{2}{|c|}{ Tidak Eksklusif } & \multicolumn{2}{|c|}{ ASI Eksklusif } & & & & \\
\hline & $\mathrm{n}$ & $\%$ & $\mathrm{~N}$ & $\%$ & $\mathrm{~N}$ & $\%$ & & \\
\hline Negatif & 24 & 82,8 & 5 & 17,2 & 29 & 100,0 & & 4,416 \\
\hline Positif & 25 & 52,1 & 23 & 47,9 & 48 & 100,0 & 0,014 & $(1,444-13,502)$ \\
\hline Total & 49 & 63.6 & 28 & 36.4 & 77 & 100.0 & & \\
\hline
\end{tabular}

Berdasarkan tabeldapat diketahui dari 29 responden dengan dukungan petugas kesehatan negatif, sebanyak $24(82,8 \%)$ responden yang memberikan ASI tidak eksklusif dan sebanyak 5 $(17,2 \%)$ responden yang memberikan ASI eksklusif. Dan dari 48 responden dengan dukungan tenaga kesehatan postif sebanyak $25(52,1 \%)$ responden memberikan ASI tidak Eksklusif dan sebanyak 23 $(47,9 \%)$ responden memberikan ASI eksklusif.
Hasil uji statistik didapat nilai $p$ value $0,014<$ a $(0,014<0,05)$ dimana $\mathrm{HO}$ ditolak sehingga dapat disimpulkan bahwa ada hubungan dukungan tenaga kesehatan dengan pemberian ASI eksklusif di Puskesmas Kalirejo Kabupaten Pesawaran tahun 2019. Dengan nilai OR didapat 4,416 artinya dukungan tenaga kesehatan positif mempunyai resiko 4,4 kali untuk memberikan ASI tidak eksklusif dibandingkan dukungan tenaga kesehatan negatif.

Tabel 10 Faktor - faktor yang berhubungan dengan pemberian ASI eksklusi

\begin{tabular}{lccccc}
\hline \multicolumn{1}{c}{ Variabel } & \multirow{2}{*}{$\mathrm{B}$} & \multirow{2}{*}{ Sig. } & \multirow{2}{*}{$\operatorname{Exp}(\mathrm{B})$} & \multicolumn{2}{c}{$95 \%$ C.I.for EXP(B) } \\
\cline { 5 - 6 } & & & & Lower & Upper \\
\hline Pengetahuan & 3.211 & .000 & 24.807 & 4.288 & 143.50 \\
Kelainan anatomis putting susu & 1.572 & .143 & 4.816 & .588 & 39.409 \\
Dukungan tenaga kesehatan & 2.023 & .012 & 7.563 & 1.558 & 36.719 \\
Pekerjaan & 2.888 & .001 & 17.952 & 3.109 & 103.66 \\
Constanta & -6.091 & & & & \\
\hline
\end{tabular}

Berdasarkan tabel diatas dapat disimpulkan bahwa dari keseluruhan proses analisa yang dilakukan ternyata variabel yang memiliki nilai $p$ value $<0,05$ yaitu variabel pengetahuan $(p=0.000$, OR: 24.907), variabel tenaga kesehatan $(p=0.012$, OR: 7,563$)$, pekerjaan $(p=0.001$, OR: 17.952), Sehingga dalam penelitian ini dapat disimpulkan bahwa pengetahuan merupakan faktor yang paling dominan dalam pemberian ASI ekslusif jika dibandingkan faktor yang lainnya karena OR paling besar yaitu 24.907.

Hasil persamaan regresi logistic bahwa pada pengetahuan, tenaga kesehatan, pekerjaan memiliki probabilitas terhadap pemberian ASI eksklusif sebesar $88.4 \%$.

\section{PEMBAHASAN}

Hubungan pengetahuan tentang Pemberian ASI Eksklusif

Hasil penelitian yang didapat bahwa pengetahuan yang dimiliki ibu dapat diubah meskipun dalam kategori pengetahuan kurang dengan harapan dapat lebih ditingkatkan lagi kemampuannya dalam memahami pentingnya pemberian ASI Eksklusif pada bayi. Setelah ibu mendapat informasi dan paham maka ibu akan menerapkan kepada bayinya untuk menyusui secara eksklusif. Dengan pemecahan masalah ini agar target pencapaian ASI Eksklusif dapat berhasil, tenaga kesehatan dapat lebih meningkatkan penyuluhan tentang ASI Eksklusif terutama perawat, bidan dan meyakinkan para ibu untuk tidak terpengaruh dengan iklan-iklan susu formula. Dan frekuensii penyuluhan juga dapat ditingkatkan yaitu setiap ada pemeriksaan ibu hamil ataupun posyandu.Metode penyuluhan dapat dilakukan dengan cara-cara yang menarik seperti memakai poster atau gambar-gambar tentang ibu menyusui, baik manfaat dan dampak dari pemberian ASI Eksklusif.

Dari hasil pengamatan yang dilaksanakan pada penelitian, peneliti berpendapat untuk dilaksanakan upaya peningkatan pengetahuan ibuibu hamil tentang ASI Eksklusif dengan upaya Dan 
prinsip untuk memberikan ASI Eksklusif 6 bulan sebaiknya disampaikan secara perlahan sejak ibu dalam masa kehamilan.Dengan demikian ibu dapat mengambil keputusan secara matang untuk pemberian ASI kepada bayinya kelak.Tidak dilakukan hanya pada ibu hamil saja tetapi pada ibu-ibu pengajian atau ibu PKK agar informasi tentang ASI Eksklusif dapat tersalurkan dan pengetahuan mereka tentang ASI Eksklusif dapat bertambah. Dengan pengetahuan dan pemahaman yang baik diharapkan ibu mempunyai kemauan yang kuat untuk memberikan ASI Eksklusif kepada bayinya, selain itu peningkatan kesadaran dari petugas kesehatan untuk memfasilitasi ibu dalam memberikan ASI Eksklusif perlu ditingkatkan dengan upaya pengawasan dalam pemberian ASI Eksklusif selama ibu dalam periode menyusui secara eksklusif.

\section{Hubungan Pekerjaan dengan Pemberian ASI Eksklusif}

Dari responden yang bekerja, terdapat responden yang memberikan ASI eksklusif hal ini dimungkinkan karena pekerjaan ibu tidak terikat, dimana ibu tidak bekerja sampai harus meninggalkan anak dari pagi sampai sore, atau adanya fasilitas ditempat ibu bekerja sehingga ibu dapat memompa asi dan memberikannya kepada anak dan adanya kebijakan dari tempat bekerja ibu yang memperbolehkan ibu untuk pulang dan memberikan asi pada bayinya, banyak cara yang dapat dilakukan oleh ibu bekerja untuk dapat terus memberikan ASI kepada bayinya apalagi jika ibu mengetahui bahwa ASI dapat di simpan di dalam kulkas dan di dalam ruangan dengan suhu yang tepat, peran petugas kesehatan sangat penting untuk dapat memberikan informasi dengan benar kepada ibu-ibu yang bekerja untuk terus memberikan ASI kepada bayinya selama 6 bulan,

Terdapat responden tidak memberikan ASI eksklusif, hal ini dimungkinkan seorang ibu bekerja akan menghabiskan waktunya di kantor, bekerja juga merupakan sumber ketegangan dan stress yang besar bagi para ibu bekerja. Mulai dari peraturan kerja yang kaku, bos yang tidak bijaksana, beban kerja yang berat, ketidakadilan yang dirasakan di tempat kerja, rekan-rekan yang sulit bekerja sama, waktu kerja yang sangat panjang, atau pun ketidaknyamanan psikologis yang dialami akibat dari problem sosial-politis di tempat kerja. Situasi demikian akan membuat ibu menjadi amat lelah, sementara kehadirannya masih sangat dinantikan oleh keluarga di rumah. Kelelahan psikis dan fisik itu lah yang sering membuat mereka sensitif dan emosional, baik terhadap anak-anak maupun terhadap suami.

Menurut pendapat peneliti pemberian informasi yang berguna bagi ibu oleh tenaga kesehatan seperti informasi bagai mana pemberian ASI pada ibu-ibu yang bekerja untuk tetap memberikan ASI Eksklusif dengan menyempatkan sebagian waktunya, dengan cara memompa atau dengan memerah ASI, lalu kemudian disimpan dan diberikan pada bayinya nanti. Kebanyakan ibu yang bekerja tidak memberikan ASI esklusif pada bayinya, tapi ada pula ibu yang bekerja dapat memberikan ASI ekslusif pada bayinya.

\section{Hubungan kelainan Puting susu dengan Pemberian ASI Eksklusif}

Menurut pendapat peneliti Responden yang tidak ada kelainan putting susu namun tidak memberikan ASI eksklusif sebanyak $56,7 \%$ hal ini disebabkan adanya faktor lain seperti kurangnya pengetahuan ibu, ibu yang bekerja maupun adanya faktor lain yang tidak diambil dalam penelitian ini seperti dukungan suami, faktor psikologis dan lain lain sehingga ibu tidak memberikan ASI secara eksklusif kepada bayinya atau adanya budaya yang kuat didalam keluarga ibu dimana bayi ada yang sudah diberi ASI sehingga ibu gagal dalam memberikan ASI eksklusif.

Dari responden yang ada kelainan putting susu, dan terdapat responden memberikan asii sebesar $11,8 \%$ hal ini dimungkinkan adanya faktor yang mendukung ibu walaupun ibu memiliki kelainan pada payudara namun ibu tetap memberikan ASI eksklusif, kemungkinan dapat diatasinya masalah tersebut sehingga tidak menghambat ibu dalam memberikan ASI ekslusif, seperti jika ibu memiliki puting susu terbenam sudah ada alat yang untuk menyambung puting susu ibu atau ibu rajin melakukan perawatan puting susu, sehingga yang awalnya ibu memiliki puting susu terbenam setelah dilakukan perawatan dapat diperbaiki atau kelainan seperti bengkak pada payudara yang dapat diatasi oleh ibu dan terdapat responden tidak memberikan ASI eksklusif.

Menurut pendapat peneliti kelainan putting susu dapat menjadi salah satu faktor pemberian ASI Eksklusif. Pada penelitian ini terbukti bahwa mastitis merupakan salah satu faktor ibu tidak memberikan ASI secara eksklusif tetapi memberikan PASI pada bayi usia dibawah 6 bulan. Responden yang mengalami mastitis enggan untuk memberikan ASI kepada bayi mereka, dengan alasan akan terasa sakit pada saat menyusui, sehingga untuk sementara digantikan dengan susu 
formula, malahan ada yang responden yang menghentikan sama sekali pemberian ASI.

\section{Hubungan dukungan tenaga kesehatan dengan Pemberian ASI Eksklusif}

Berdasarkan hasil penelitian diketahui dari 29 responden dengan dukungan petugas kesehatan negatif, sebanyak $24(82,8 \%)$ responden yang tidak memberikan ASI eksklusif hal ini sejalan dengan teori yang mengungkapkan bahwa peran petugas dalam memotivasi ibu untuk memberikan ASI sangat penting guna keberhasilan pemberian ASI eksklusif sehingga jika petugas tidak aktif berperan dalam pemberian ASI eksklusif maka akan mempengaruhi perilaku ibu dalam memberikan ASI dan sebanyak $5 \quad(17,2 \%)$ responden yang memberikan ASI eksklusif hal ini dikarenakan adanya faktor lain seperti adanya dukungan dari suami dan pengatahuan ibu yang baik sehingga walaupuin petugas tidak berperan aktif namun responden tetap memberikan ASi secara eksklusif.

Dan dari 48 responden dengan dukungan tenaga kesehatan postif sebanyak $25 \quad(52,1 \%)$ responden tidak memberikan ASI Eksklusif hal ini kemungkinan adanya faktor lain yang membuat ibu tidak memberikan asi secara ekkslusif seperti adanya kelainan pada puting susu ibu sehingga ibu mengganti dengan memberikan susu formula dan sebanyak $23(47,9 \%)$ responden memberikan ASI eksklusif menurut pendapat peneliti Sikap petugas kesehatan untuk menyadari bahwa posyandu merupakan hal yang utama untuk meningkatkan derajat kesehatan, hal ini dapat menimbulkan perilaku dengan pemberian ASI eksklusif . Sikap yang positif akan mempengaruhi perubahan perilaku yang positif. Berdasarkan hasil penelitian dan teori, peneliti berpendapat bahwa sikap petugas kesehatan akan berpengaruh terhadap perilaku Pemberian ASI Eksklusif.

\section{KESIMPULAN}

Sebagian besar responden tidak ASI eksklusif yaitu sebanyak $49(63,6 \%)$ responden dan Asi Ekslusif sebanyak $28(36,4 \%)$. ibu yang tidak bekerja yaitu sebanyak $42(54,5 \%)$ responden, responden yang berpengetahuan kurang baik yaitu sebanyak $54(70,1 \%)$ responden, responden tidak ada kelainan putting susu yaitu sebanyak 59 $(76,6 \%)$ responden dan responden mengungkapkan dukungan tenaga kesehatan positif yaitu sebanyak $48(62,3 \%)$ responden.Ada hubungan pekerjaan dengan pemberian ASI eksklusif di Puskesmas Kalirejo Kabupaten Pesawaran tahun 2019 ( $p$-value $=0,000$ dan OR10,333).Ada hubungan pengetahuan dengan pemberian ASI eksklusif di
Puskesmas Kalirejo Kabupaten Pesawaran tahun 2019 ( $p$-value $=0,000$ dan OR 15,840).Ada hubungan kelainan Puting susu dengan pemberian ASI eksklusif di Puskesmas Kalirejo Kabupaten Pesawaran tahun 2019 ( $p$-value 0,035 dan OR 5,735).Ada hubungan dukungan tenaga kesehatan dengan pemberian ASI eksklusif di Puskesmas Kalirejo Kabupaten Pesawaran tahun 2019 ( $p$-value $=0,014$ dan OR 4,416). Hubungan (pengetahuan, pekerjaan, kelainan bentuk putting susu dan dukungan tenaga kesehatan) dengan pemberian ASI eksklusif di Puskesmas Kalirejo Kabupaten Pesawaran tahun 2019 sebesar $88,4 \%$.

\section{SARAN}

Hasil penelitian ini diharapkan dapat menjadi masukan bagi para ibu yang memiliki bayi, untuk memberikan ASI secara eksklusif selama 6 bulan dalam rangka meningkatkan kualitas bayi dan pemenuhan nutrisi serta peningkatan kekebalan tubuh pada bayi dan masukan bagi masyarakat untuk dapat membantu dalam meningkatkan program pemberian ASI Eksklusif pada ibu ke bayi seperti menyediakan tempat untuk ibu menyusui

Hasil penelitian ini diharapkan menjadi bahan masukan bagi dinas kesehatan untuk terus mempromosikan pentingnya pemberian ASI Eksklusif selama 6 bulan untuk meningkatkan pemenuhan nutrisi dan kekebalan tubuh bayi dan dapat memberikan gambaran dan masukan bagi pembuat kebijakan di institusi tentang pemberian ASI eksklusif sehingga dapat lebih meningkat target ASI eksklusif secara lebih baik lagi misalnya membuat brosur tentang manfaat dari memberikan ASI eksklusif kepada bayi, memberikan penyuluhan, dan lain-lain dimana kegiatan tersebut mendukung program pemberian ASI eksklusif.Berdasarkan hasil penelitian, maka peneliti memberikan saran kepada Dinas Kesehatan Kabupaten Pesawaran agar memonitor secara intens program - program yang ada, apakah sudah berjalan sesuai dengan yang direncanakan dan apa kendala dilapangan, dan petugas Perkesmas perlu mendapatkan pelatihan terkait dengan Pemberian ASI eksklusif pada bayi, serta menggalakan dan meningkatkan program kesehatan ibu dan anak, khususnya bagi ibu menyusui. Dapat dilakukan penyebaran informasi berupa pengembangan media informasi seperti leaflet, CD tentang ASI, Poster baik kepada ibu menyusui maupun kepada keluarga terkait dengan ASI eksklusif, menambah sarana dan prasana penunjang ASI eksklusif seperti pojok konseling untuk ibu menyusui. Bagi keluarga diharapkan peran serta aktif pasanga atau suami untuk memberikan dukungan terhadap pemberian 
ASI eksklusif karena kesuksesan menyusui bukan merupakan tanggung jawab salah satu pihak melainkan tanggung jawab bersama suami dan istri.Keluarga bertanggung jawab untuk melakukan komunikasi dan memberikan dukungan yang baik dalam memenuhi kebutuhan fisik dan psikologis ibu menyusui.Tenaga kesehatan dan konselor laktasi hendaknya dapat memberikan edukasi kepada ibu hamil yang menitikberatkan pada peningkatan sikap dan kepercayaan diri agar ibu hamil memiliki intensi yang kuat untuk memberikan ASI eksklusif.Tempat kerja diharapkan dapat mewujudkan kebijakan tempat kerja ramah laktasi dengan memberikan edukasi, fasilitas ruang menyusui, dan kebijakan tertulis bagi ibu menyusui.

\section{DAFTAR PUSTAKA}

Lampung, D. K. P. (2016). Profil Provinsi Lampung Tahun 2015. Bandar Lampung: Dinas Kesehatan Pemerintah Provinsi Lampung.

Lampung, D. K. P. (2017). Profil Provinsi Lampung Tahun 2016. Bandar Lampung: Dinas Kesehatan Pemerintah Provinsi Lampung.

Febriyanti, H. (2018). Faktor-faktor yang

Berhubungan dengan Pemberian Asi

Eksklusif pada Tenaga Kesehatan yang

Memiliki Bayi di Wilayah Kabupaten

Pringsewu Tahun 2017. Midwifery Journal:

Jurnal Kebidanan UM. Mataram, 3(1), 38-47.

Jateng, D. (2011). Profil Kesehatan Jawa Tengah. Semarang: Depkes

KeMenKes, R. I. (2016). Profil kesehatan Indonesia tahun 2015. Jakarta Kementeri Kesehatan Republik Indonesia.

Notoatmodjo, S. (2012).Metodologi penelitian kesehatan (Cetakan VI).Jakarta: Penerbit PT Rineka Cipta.
Pesawaran, D. K. K (2018). Profil Kesehatan Kabupaten Pesawaran Tahun 2017. Gedong Tataan: Dinas Kesehatan Kabupaten Pesawaran.

Rahmawati, M. D. (2010). Faktor-faktor yang mempengaruhi pemberian asi eksklusif pada ibu menyusui di kelurahan Pedalangan kecamatan Banyumanik kota Semarang. Jurnal Kesehatan Kusuma Husada.

Swarjana, I. K., \& SKM, M. (2012). Metodologi penelitian kesehatan. Penerbit Andi.

Sari, L. A. (2017).Gambaran Tingkat Pengetahuan Ibu Menyusui Tentang ASI Eksklusif di Puskesmas Gamping 2 Sleman (KTI, Sekolah Tinggi IImu Kesehatan Jenderal Achmad Yani).

Septikasari, M. (2018).Status gizi anak dan faktor yang mempengaruhi.Yogyakarta: UNY Press.

Setyowati, H. (2008). Bayi Cerdas, Kenapa Tidak. Jakarta: Libri.

Soetjiningsih, R. G. (2013). Buku Tumbuh Kembang Anak Edisi 2. Jakarta: Penerbit Buku Kedokteran EGC.

Suherni, H. W., \& Rahmawati, A. (2009). Perawatan Masa Nifas. Fitramaya, Yogyakarta.

Sulistyawati, A. (2009). Buku Ajar Asuhan Kebidanan Pada Ibu Nifas. Yogyakarta: Andi Offset, 1-6.

Sulistyoningsih, H. (2012). Gizi untuk kesehatan ibu dan anak. Yogyakarta: Graha IImu.

Utami, U. P. (2018). Hubungan Dukungan Bidan dan Dukungan Keluarga Terhadap Pemberian ASI Eksklusif di Wilayah Kerja Puskesmas Umbulharjo I Kota Yogyakarta (Skripsi, Universitas 'Aisyiyah). 